Brit. J. industr. Med., 13, 163.

\title{
OCCUPATIONAL MEDICINE AS A VOCATION
}

\author{
BY
}

JAMES A. SMILEY

Belfast

Those of us who are engaged in the practice of medicine within industry have at some time been forced to ask ourselves, "Why do men work ?", and no single simple answer emerges. Most of us work because work is an economic necessity. "In the sweat of thy brow shalt thou eat bread (Genesis iii : 7)." Work is a condition of man's existence but almost inevitably most of us would avoid it if we could. That we do not make more strenuous efforts to do so is probably because although labour is not sweet its fruits often are. The satisfaction of doing a job well, the sense of achievement, or the genuine commendation of a supervisor can compensate for hours of drudgery. But these rewards are rare and what makes work more bearable for most men and women day in and day out for years on end, are its by-products - the companionship of the group, the possibility of earning enough to buy a television set or some adjunct to a hobby or a better education for a boy at home. Some get through the day's work not because they enjoy it but because inside the working group they hold a recognized and unique place into which they or almost they alone can fit. One character inevitably becomes a shop steward, another the wag who sends the new apprentice for "sky-hooks" or a "soft-faced hammer", another the man who is the confidant of all in trouble. Some work because work is a habit, some because it gives them opportunities for day-dreaming, and yet others because ambition is the spur. The philosophy and creed of Calvinism which regards work as a moral and religious duty has a diminishing number of devotees in western Europe though they may still be found in Scotland and the Low Countries. In Russia and elsewhere the dynamism of the Communist faith exerts on party members much the same kind of influence. All or any of these considerations apply to every form of work except perhaps that of the creative artist whose motivation is an inner compulsion which often he does not understand. For him there is no divorce between work and leisure. Creative activity is his life and the power of it is irresistible.
The practice of medicine impinges on every facet of human life and since the dawn of medicine its practitioners have interested themselves in the relationship between occupation and health. Hippocrates (born 460 B.c.) well knew and described the toxic properties of lead. Galen (born 131 B.c.) referred to the diseases peculiar to miners, tanners, and fullers. Pliny the Elder (A.D. 23-79) described the masks worn by those employed in dusty trades. Paracelsus (1493-1541) wrote a monograph on Miners' Sickness and Other Miners' Diseases and in more recent times-the eighteenth centuryBernadino Ramazzini wrote his classic De Morbis Artificum Diatriba. Percival Pott described the scrotal cancer of chimney-sweeps, Willan the skin lesions of bakers, while later Thomas Percival of Manchester and Charles Turner Thackrah of Leeds were the prophets of Sir Thomas Legge who made industrial medicine his life work.

The present increased awareness of the relationship between occupation and health is mainly due to the rapid industrialization of modern society and to the ever-growing multiplication of specialities in all the arts and sciences, because of our restless haste to accumulate, and sometimes to use knowledge. The subject is not new and has called our fathers and brethren throughout all generations. But what may be new is the increasing number of men and women who are specializing in the application of medicine to industry. The organization of industrial medicine is the inevitable reply to a clamant social need-just as public health was organized in the nineteenth century to combat the evils resulting from urbanizing a rural society. The present development of industrial medicine behoves us to examine afresh our vocation, Why do we do this work?

Inevitably and fortunately in an expanding enterprise there are always a few men who are obsessed and inspired by its ideals and possibilities. That our own branch of the profession in this country is producing such men cannot be doubted. We need not fear for our future leadership in the years which lie immediately ahead. But what impels the growing 
number of younger men and women to practise medicine inside industrial groupings ? One of the glories of working within industry is the intense satisfaction to be derived from working as a member of a team-a team so diverse in its interests as to include works managers, engineers, chemists, personnel managers, nurses, shop stewards, and many others. The contribution made in working and associating with colleagues in a common task may be considerable, the contribution one receives is very great. Its results are not only of value to the community but have personal implications also. Not infrequently the doctor in a factory slips into that special little niche which only he can fill and the privilege of the unique contribution which only he can make is infinitely rewarding. Chaucer knew him:

"With us ther was a Doctour of Phisyk. In al this world ne was ther noon him lyk."

We are fortunate in the great tradition of medicine which we inherit-a tradition of integrity and of independence, a tradition of kindliness and often of self-sacrifice. Even today practitioners of medicine derive immense satisfaction because they are not just another type of technician. This position must be fought for by maintaining the traditionally high standard of personal conduct. The techniques of our profession continue to multiply but their limits are set by one over-riding consideration, the inherent worth of each individual. No medical practitioner would allow men to work in an atmosphere of unknown toxicity merely to discover what the effect might be. The acceptance of the essential importance of the individual is part and parcel of our inheritance as doctors, powerfully reinforced by the Christian religion. However ineffective that religion may appear to be today there is no doubt of its influence in the formative days of British medicine. There is a danger that in the need for organization in a complex society the individual may be sacrificed. Humanism pays lip service to the idea that human personality has supreme value, but that idea may soon be submerged in any planned society. We as doctors are constantly in touch with people in need, always aware of human frailty, but ever conscious of the potentialities of goodness and occasionally of greatness in those amongst whom we work. We should remind ourselves from time to time of the doctrine of the sanctity of personality in which every liberal society has its roots. Consciously or unconsciously doctors accept the standards implicit in all this but within the limits set by our acceptance of these standards we are governed by the considerations which apply to any trade or profession. We must preserve our idealism but there is no place in industrial medicine for a sentimental paternalistic approach. We must always strive not only to achieve the highest competence of which we are capable but we should be constantly seeking new techniques and through them to make whatever contribution we can to our community. That is but our common social duty. As Dorothy Sayers (1941) puts it:-

\begin{abstract}
"The way in which the work is done is governed by no sanction except the good of the work itself: and religion has no direct connection with that except to insist that the workman should be free to do his work well according to its own integrity."
\end{abstract}

Later she illustrates this in discussing the choice of actors for a religious play and continues "the right kind of actor with no morals would give a far more reverent and seemly performance than a saintly actor with the wrong technical qualifications". No doubt the technically qualified saint would be ideal. But, unfortunately, they are very rare in any situation. It behoves us, then, not only to be technically efficient at the work to which we have set our hands but because of its nature we should see before us the vision of industrial environment in which we and our fellows can, if we will, find freedom in service. In the first century St. Paul knew that concept and found his freedom in his bondage to an ideal.

Men and women are in an environment (psychological as well as physical) which is constantly changing; there is generally a delay in the adaptation, which emphasizes the importance of the role played by doctors in industry. Hand skills are being replaced by machine skills; in many respects the " boss" has become impersonal; and there is often no identifiable focus for loyalty, except perhaps the shop steward. The working group is frequently subjected to new processes or to a change in routine. The most resilient personalities do not appear to be affected by these changes. However, Russell Fraser (1947) found that $9 \%$ of men and $13 \%$ of women in a sample of 3,000 industrial workers had suffered from definite disabling neurotic illness and that this type of illness caused $25-33 \%$ of all sickness, which again emphasizes the importance of the task that doctors have been called upon to play in industry. Our vocation lies not only in psychological medicine but also in general and social medicine. One man may find that the prime need of the industry in which he is engaged is the organization of a casualty service, another may be concerned with dust, and yet another with toxicological or similar hazards. The variety is almost infinite but all the time the concern is for individual men and women. Happy is the family doctor who combines general practice 
with occupational medicine, for he is in the unique position of knowing many of his patients not only as members of family groups in which they live a relatively small part of their lives (for families grow up and disperse) but of changing yet continuing industrial groups as well. The influences which act on people during their working lives can be known only to those who have experienced or investigated them. Opportunities for research are abundant and as a rule the necessary facilities are available. Before we can prescribe for the individual we must know the cause of his breakdown and the prescription is often one which only the factory doctor can make-the modification of a process, the alteration of a man's working hours, the transfer to a more congenial group. The bounds of ignorance are gradually being pushed back and in these advances doctors in industry have played and are playing a notable part. It is a part which is the quintessence of our vocation.

Because individuals aggregate to form groups in which they are subjected to similar environmental influences, the reactions of these groupings must be studied. Morris (1955) points out that "epidemiology", which is one aspect of this study,

"... . supplements the clinical picture: by asking questions that cannot be asked in clinical study-about the health of the community and of sections of it, present and past; by setting clinical problems in community perspective, describing their behaviour as group not individual phenomena, indicating their dimensions and distributions, and how much, and where, action is needed;....",

Earlier in his paper Morris suggests a number of problems which require elucidation. Some of these are on our own doorstep- " the effect of more married women going out to work, of less physical activity in work and more bodily sloth generally; of multiple chemical and physical exposures, known and potentially hazardous; ... "-not to speak of occupational dermatitis and its relationship, if any, to emotional instability, the various aspects of the incidence of accidents, of chronic bronchitis, of the effects of noise, and a host of others. Many contributions have been made on some of these and other subjects, by doctors in industry. The opportunities, the privilege, and the exhilaration of isolating one little iota of truth in the vast welter of surmise, are open to every practitioner of medicine in industry.
The factory doctor knows his patients intimately as individuals but he can, if he will, know them too as members of a social group.

There is a separation if not quite a divorce of clinical medicine from social medicine today. It may be that those of us who accept clinical responsibilities (as perforce to some extent we must) and at the same time have the maintenance of the health and welfare of the industrial population while at work, as our duty, will be agents in their reconciliation.

The approach, from an interest in individuals to a concern for coherent groups, has been common to most of our predecessors. To realize that the tradition persists, one has only to think of Henry (1946) whose interest in cancer of the scrotum as a clinical problem led to his study of it as an occupational one-and to its virtual elimination. In more recent years a growing number of men and women have entered our speciality from the opposite direction. With an interest in public health and the behaviour of aggregations of people, they have been led to the industrial field. Their contribution to the techniques of observation and analysis are of the utmost value. Nevertheless occupational medicine remains very largely a clinical subject presenting a wide variety of facets.

It is, unfortunately, true that as in every other branch of the profession there are a few who are so immersed in the routine of the job that they have neither the time nor the inclination to sit back and think of the essential significance of their work. But the work they do is still important. What they miss is the inspiration of knowing that they belong to a group of men and women who are dedicated to the idea that the traditions and the techniques of medicine can contribute immeasurably to the health and happiness of the industrial community. Occupational medicine as a vocation beckons to it technically good doctors, generous in their sympathies, liberal in their sentiments, humble in their ignorance, adventurous in their seeking, and courageous when, as sometimes happens, they are misunderstood by those whom they serve.

\section{REFERENCES}

Fraser, T. R. C. (1947). Rep. industr. Hlth Res. Board (Lond.), No. 90.

Henry, S. A. (1946). Cancer of the Scrotum in Relation to Occupation. Oxford University Press, London.

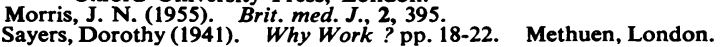

